\title{
Differential memory persistence of odor mixture and components in newborn rabbits: competition between the whole and its parts
}

\author{
Gérard Coureaud ${ }^{1}$, Thierry Thomas-Danguin ${ }^{1}$, Frédérique Datiche ${ }^{1}$, Donald A. Wilson ${ }^{2}$ and \\ Guillaume Ferreira ${ }^{3,4}$
}

' Centre des Sciences du Goût et de I'Alimentation (CSGA), UMR 6265 CNRS, UMR 1324 INRA, Université de Bourgogne, Dijon, France

${ }^{2}$ Department of Child and Adolescent Psychiatry, New York University Langone School of Medicine, New York, NY, USA

${ }^{3}$ Nutrition and Integrative Neurobiology Group, INRA UMR 1286, Bordeaux, France

${ }^{4}$ Université de Bordeaux, Bordeaux, France

Edited by:

Anne-Marie Mouly, Centre de

Recherche en Neurosciences de Lyon, France

Reviewed by:

Christiane Linster, Cornell

University, USA

Mouna Maroun, University of Haifa,

Israel

${ }^{*}$ Correspondence:

Gérard Coureaud, Centre des

Sciences du Goût et de

I'Alimentation (CSGA), UMR 6265

CNRS, UMR 1324 INRA, Université

de Bourgogne, 9E Boulevard

Jeanne d'Arc, 21000 Dijon, France

e-mail: gerard.coureaud@

u-bourgogne.fr
Interacting with the mother during the daily nursing, newborn rabbits experience her body odor cues. In particular, the mammary pheromone (MP) contained in rabbit milk triggers the typical behavior which helps to localize and seize the nipples. It also promotes the very rapid appetitive learning of simple or complex stimuli (odorants or mixtures) through associative conditioning. We previously showed that $24 \mathrm{~h}$ after MP-induced conditioning to odorants $A$ (ethyl isobutyrate) or $B$ (ethyl maltol), newborn rabbits perceive the $A B$ mixture in a weak configural way, i.e., they perceive the odor of the $A B$ configuration in addition to the odors of the elements. Moreover, after conditioning to the mixture, elimination of the memories of $A$ and $B$ does not affect the memory of $A B$, suggesting independent elemental and configural memories of the mixture. Here, we evaluated whether configural memory persistence differs from elemental one. First, whereas 1 or 3-day-old pups conditioned to A or B maintained their responsiveness to the conditioned odorant for 4 days, those conditioned to $A B$ did not respond to the mixture after the same retention period. Second, the pups conditioned to $A B$ still responded to $A$ and $B 4$ days after conditioning, which indicates stronger retention of the elements than of the configuration when all information are learned together. Third, we determined whether the memory of the elements competes with the memory of the configuration: after conditioning to $A B$, when the memories of $A$ and $B$ were erased using pharmacological treatment, the memory of the mixture was extended to day 5 . Thus, newborn rabbits have access to both elemental and configural information in certain odor mixtures, and competition between these distinct representations of the mixture influences the persistence of their memories. Such effects certainly occur in the natural context of mother-pup interactions and may contribute to early acquisition of knowledge about the surroundings.

Keywords: Oryctolagus cuniculus, newborn, odor mixture, configural perception, stimulus representation, retention, memory persistence

\section{INTRODUCTION}

In some cases, mixtures of volatile molecules are perceived as a collection of independent, identifiable elements; the perception is then elemental (e.g., Laing and Francis, 1989; Laska and Hudson, 1993; Linster and Cleland, 2004). However, some mixtures induce a configural processing. Then, the mixture gives rise to either a unique and novel odor quality, different from the odor qualities of the elements (robust configural perception; e.g., Smith, 1996; Jinks and Laing, 1999; Kay et al., 2005), or to a novel quality perceived in addition to the qualities of the odorants (weak configural perception; Rescorla, 1973; Kay et al., 2005). Configural odor processing has been described with different mixtures and different approaches in a variety of species from invertebrates to vertebrates, including humans (e.g., Derby et al., 1996; Linster and Smith, 1999; Valentincic et al., 2000; Wise and Cain, 2000; Deisig et al., 2001; Wiltrout et al., 2003; Mandairon et al., 2006; Riffell et al., 2009; Gottfried, 2010; Wilson and Sullivan, 2011). For instance, data in human adults revealed that a mixture of two odorants $(\mathrm{AB})$, one smelling like strawberry (A: ethyl isobutyrate) and the other like caramel (B: ethyl maltol), generates the configural perception of a pineapple odor at a specific ratio of A/B (30/70 v/v; Le Berre et al., 2008, 2010; Barkat et al., 2012). Interestingly, recent results in a newborn mammal, the newborn rabbit, showed similar configural processing abilities with the same $A B$ mixture, at the same ratio. Indeed, after single appetitive conditioning to odorant $\mathrm{A}$ or to odorant $\mathrm{B}$ by pairing 
with the mammary pheromone (MP) (naturally contained in rabbit milk and experimentally used as unconditioned stimulus in associative conditioning procedure; Coureaud et al., 2006, 2010), rabbit pups respond to the conditioned element and respectively to the $\mathrm{AC}$ or $\mathrm{BC}$ mixtures ( $\mathrm{C}$ : guaiacol). However, they do not respond to the $\mathrm{AB}$ mixture. These results suggest that they perceive $\mathrm{AB}$ differently from the odors of $\mathrm{A}$ and of $\mathrm{B}$, while they perceive $\mathrm{AC}$ or $\mathrm{BC}$ as the sum of their component odors (Coureaud et al., 2008, 2009a, 2011a). Furthermore, after single conditioning to the $\mathrm{AB}$ mixture, rabbit pups respond to the components $\mathrm{A}$ and $\mathrm{B}$ in addition to $\mathrm{AB}$, indicating that the $\mathrm{AB}$ mixture is perceived in a weak configural way (Coureaud et al., 2008). Very recently, combining behavioral approaches with pharmacological tools, we provided another confirmation of this neonatal weak configural perception of $\mathrm{AB}$ and demonstrated that rabbit pups memorize the $\mathrm{AB}$ configuration independently (at least in part) from the representations of each element. After conditioning to $\mathrm{AB}$, amnesia of $\mathrm{A}$ and $\mathrm{B}$ did not propagate to $A B$ : pups that did not respond to either $A$ or $B$ still responded to $\mathrm{AB}$ (Coureaud et al., in press). Thus, after $\mathrm{AB}$ conditioning, distinct elemental and configural memories of the mixture are created.

In the previous studies in newborn rabbits, memories of the elements $\mathrm{A}$ and $\mathrm{B}$ or of the $\mathrm{AB}$ configuration were evaluated 24 or $48 \mathrm{~h}$ after conditioning, which are the optimal delays for responsiveness to a stimulus conditioned by single pairing with the MP (Coureaud et al., 2006). However, to date, whether memory persistence of the configural odor of the $\mathrm{AB}$ mixture differs from that of the odorants $\mathrm{A}$ and $\mathrm{B}$ (also detected in the mixture) had never been evaluated; here, we hypothesized that they could be distinguished. This issue constituted the first and main goal of our study. Besides understanding early memory and perception in the rabbit, this evaluation could more broadly help provide additional and original information on the general topic of odor object perception in mammals. Indeed, as said above, a perceptual match has been evidenced for the $\mathrm{AB}$ mixture between rabbit pups and human adults, which suggests a relative conservation in the processing of certain odor mixtures across species.

Our second goal aimed to assess whether memory retention of the configural $\mathrm{AB}$ odor and of the elemental odors of $\mathrm{A}$ and $\mathrm{B}$ depends on the age of the pups at conditioning. Indeed, it is known in newborn mammals (especially in altricial mammals, which develop very rapidly) that the meaning acquired by a conditioned odorant can change from one day to another (e.g., Barr et al., 2009; Sullivan and Holman, 2010). In previous experiments, conditioning was mainly performed in 2-day-old rabbit neonates. In the present study, conditioning was therefore conducted either 1 or 3 days after birth to determine the influence of development on the perception and memory of a complex odor stimulus.

These two issues were evaluated by taking advantage of the configural nature of the previously described $\mathrm{AB}$ mixture. To date, this is the only mixture which has been extensively characterized regarding its perceptual properties (weak configural perception) in the rabbit both in terms of behavior (Coureaud et al., 2008, 2009a, 2011a; Sinding et al., 2011), memory (Coureaud et al., in press) and brain processing (Schneider et al., in preparation). To that goal, we conditioned either 1- or 3-day-old pups to simple odorants A or B, or to their binary mixture, and assessed the retention of the conditioned stimuli from 24 to $96 \mathrm{~h}$ after conditioning using independent groups for each stimulus and each retention interval (Experiment 1). Pups conditioned to the $\mathrm{AB}$ mixture were also tested for their responsiveness to $\mathrm{A}$ and to $B$ with the aim to evaluate, by means of a within-subject analysis, whether responsiveness to $\mathrm{AB}$ differed over time from that of the single odorants (Experiment 2). Finally, as differences appeared in the responsiveness to the mixture and to its odorants in the first two experiments, we determined whether competition occurred between the memory of $\mathrm{AB}$ and the respective memories of $\mathrm{A}$ and $\mathrm{B}$ created during conditioning to the whole mixture (Experiment 3 ). Indeed, interference and competition between different associative memories have been classically reported (e.g., Eisenberg et al., 2003; Suzuki et al., 2004; Bradfield and Balleine, 2013) and might contribute to the present results. Therefore, we either prevented the formation of the configural memory by successive conditioning to the single odorants only, or erased the elemental memory after initial conditioning to the $\mathrm{AB}$ mixture followed by separate reactivations of odorants $\mathrm{A}$ and $\mathrm{B}$ and amnesiainducing anisomycin (AN) injection (Coureaud et al., 2009b, 2011b, 2013). We then evaluated whether these two procedures influenced the responsiveness to the $\mathrm{AB}$ mixture after a long retention interval.

\section{MATERIALS AND METHODS ANIMALS AND HOUSING CONDITIONS}

Males and females New-Zealand rabbits Oryctolagus cuniculus (Charles River strain, L'Arbresle, France) from the Centre de Zootechnie of the University of Burgundy (Dijon) were kept in individual cages. A nest box $(0.39 \times 0.25 \times 0.32 \mathrm{~m})$ was added on the outside of the pregnant females' cages 2 days before delivery (day of delivery was day 0 ; $\mathrm{d} 0$ ). To equalize pups' nursing experience, all females had access to their nest between 11:3011:45 a.m. This procedure allowed females to follow the brief (3-4 min) daily nursing of the species (Zarrow et al., 1965). Animals were kept under a constant 12:12 light:dark cycle (light on at 7:00 a.m.) with ambient air temperature maintained at 21$22^{\circ} \mathrm{C}$. Water and pelleted food (Lapin Elevage 110, Safe, France) were provided ad libitum. In the study, 524 newborns (from 106 litters) were used.

The study was carried out under the local, institutional and national rules (French Ministries of Agriculture, and of Research and Technology) regarding the care and experimental use of the animals. All experiments were conducted in accordance with ethical rules enforced by French law, and were approved by the Ethical Committee for Animal Experimentation (no. 2406).

\section{ODORANTS}

The stimuli consisted of 2-methylbut-2-enal (the Mammary Pheromone, MP, CAS\# 497-03-0), ethyl isobutyrate (odorant A, CAS\# 97-62-1), ethyl maltol (odorant B, CAS\# 4940-11-8) for pure components, and of the $\mathrm{AB}$ mixture. This mixture included $0.3 \times 10^{-5}$ and $0.7 \times 10^{-5} \mathrm{~g} / \mathrm{ml}$ of components $\mathrm{A} / \mathrm{B}$; the $30 / 70 \mathrm{v} / \mathrm{v}$ 
ratio elicits the configural perception of a pineapple odor in human adults due to blending properties (Le Berre et al., 2008, 2010; Barkat et al., 2012), and weak configural perception in newborn rabbits (Coureaud et al., 2008, 2009a, 2011a; Sinding et al., 2011).

The MP allowed inducing the learning by the pups of odorant $\mathrm{A}$, odorant $\mathrm{B}$, or the $\mathrm{AB}$ mixture through associative conditioning (see below). It was used at $10^{-5} \mathrm{~g} / \mathrm{ml}$, a concentration known to be highly efficient to promote conditioning (Coureaud et al., 2006). Thus, the A-MP and B-MP blends were prepared at a final concentration of $10^{-5} \mathrm{~g} / \mathrm{ml}$ of each constituent. The AB-MP blend included $1 \times 10^{-5} \mathrm{~g} / \mathrm{ml}$ of MP and 0.3 and $0.7 \times 10^{-5} \mathrm{~g} / \mathrm{ml}$ of odorants $\mathrm{A}$ and $\mathrm{B}$.

Single odorants A and B were also used in the reactivation procedure (Experiment $3 \mathrm{~b}$ ) at a concentration of $10^{-5} \mathrm{~g} / \mathrm{ml}$.

In all experiments, we deliberately kept constant the overall concentration of the different stimuli (single odorants or $\mathrm{AB}$ mixture and blends; $10^{-5} \mathrm{~g} / \mathrm{ml}$ ) and maintained this constancy between conditioning and testing to avoid direct influence of the concentration on our results and to focus on the influence of complexity (single odorant vs. mixture).

All the odorants were purchased from Sigma-Aldrich (SaintQuentin Fallavier, France) and all the final solutions were prepared in a solvent composed of $0.1 \%$ of ethanol (anhydrous, Carlo Erba, Val de Reuil, France) and 99.9\% of MilliQ water (Millipore, Molsheim, France).

\section{ODOR CONDITIONING, REACTIVATION AND PHARMACOLOGICAL TREATMENT}

Conditioning sessions were run on day 1 or 3 after birth in an experimental room close to the breeding room. The pups from an individual litter were transferred by groups of 5 (usual case) or 4 (Experiment 3b) into a box maintained at room temperature. The MP-induced conditioning was run following a procedure previously described (e.g., Coureaud et al., 2006, 2008, 2009a,b, 2013; Sinding et al., 2011; Charra et al., 2013). This procedure offered the advantage of being extremely rapid (single trial) and appetitive (thus avoiding the possible modulation of responsiveness due to the negative emotional state that may occurred after aversive conditioning).

In most cases, just before the conditioning session, $4 \mathrm{ml}$ of the A-MP (Experiment 1), B-MP (Experiment 1) or AB-MP (Experiments 1, 2 and $3 \mathrm{~b}$ ) blends were pipetted on a pad $(19 \times$ $14 \mathrm{~cm}, 100 \%$ cotton) then held $2 \mathrm{~cm}$ above the pups for $5 \mathrm{~min}$. The conditioning occurred $1 \mathrm{~h}$ before the daily nursing (10:30 a.m.) to equalize the pups' motivational state and limit the impact of satiation on behavioral responses (Montigny et al., 2006). Two minutes after the end of the conditioning, the pups were individually marked with ink and returned to their nest. The box containing the pups was rinsed with alcohol and with distilled water after each conditioning session.

In one group (Experiment 3a), the procedure was the same except that pups were conditioned successively to odorants A and $\mathrm{B}$ : they were exposed to the A-MP blend for $2.5 \mathrm{~min}$ (for the half of the pups, randomly chosen, and B-MP for the other half), then transferred to a second box in which they remained non stimulated for $1 \mathrm{~min}$ before being exposed to the B-MP (or AMP) blend for $2.5 \mathrm{~min}$.

Finally, in two other groups (Experiment 3b), $24 \mathrm{~h}$ after the conditioning to the $\mathrm{AB}$ mixture, the memory of pups was reactivated by exposure to odorant $A$ then odorant $B$ in half of the pups (or conversely in the other half) following the same procedure than above (2.5 min per odorant, delay inter-stimulation: $1 \mathrm{~min}$ ). Immediately after reactivation, anisomycin (AN; SigmaAldrich) was injected to the half of the pups (42 mg/kg, i.p.) after dilution in $0.9 \% \mathrm{NaCl}$ solution and adjustment to $\mathrm{pH} 7.2$ with $1 \mathrm{~N} \mathrm{HCl}$. The AN was used after reactivation performed at $24 \mathrm{~h}$ as we have previously demonstrated the effectiveness of this procedure in erasing memory of odor element(s) in newborn rabbits (Coureaud et al., 2009b, 2011b, 2013, in press). Control for the effect of AN injection was carried out with the other half of animals, which received saline $0.9 \%$. As in other studies with newborn or adult mammals (e.g., Davis and Squire, 1984; Gruest et al., 2004; Desgranges et al., 2008) we considered that AN in newborn rabbits may induce a real amnesia and not a perturbation in responsiveness due to an aversive effect. Pups were returned to the nest just after AN or saline injection.

\section{BEHAVIORAL ASSAY}

The behavioral assay occurred $24,48,72$ or $96 \mathrm{~h}$ after the conditioning, i.e., on days 2, 3, 4 or 5 when the conditioning occurred on day 1 , and on days 4, 5, 6 or 7 when it happened on day 3 . The assay was run in the experimental room previously used for conditioning and reactivation, and happened also $1 \mathrm{~h}$ before the daily nursing to limit the impact of satiation on motivation and behavioral responsiveness (Montigny et al., 2006). It consisted of an oral activation test during which a pup was immobilized in one gloved hand of the experimenter, its head being left free. The odor stimulus was presented for $10 \mathrm{~s}$ with a glass rod 0.5 $\mathrm{cm}$ in front of the nares (e.g., Coureaud et al., 2006, 2008, 2011a, 2013). A test was positive when the stimulus elicited headsearching movements (vigorous, low amplitude horizontal and vertical scanning movements displayed after stretching towards the rod) usually followed by grasping movements (labial seizing of the rod extremity). Non-responding pups displayed no response except sniffing. Pups were tested in groups of 4 or 5 (same groups than during the conditioning), and only once, on a given day (i.e., different groups were tested on different days).

In Experiment 1, the pups were tested for their responsiveness to one stimulus only, except those which were conditioned to the $\mathrm{AB}$ mixture. The latter were indeed tested to $\mathrm{AB}$ but also (these results are the results of Experiment 2) to odorants $A$ and $B$. In Experiment 3, the pups were tested to A, B and AB. Successive testing involved the presentation of a first stimulus to a pup, then a second stimulus to another pup, and so on with an inter-trial interval of $60 \mathrm{~s}$. The order of stimuli presentation was systematically counterbalanced from one to another pup. If a pup responded to a stimulus, its nose was softly dried before the next stimulation. The pups were immediately reintroduced in their nest after testing. 


\section{STATISTICS}

Each group was composed of 18-20 pups except the groups of Experiment $3 \mathrm{~b}$ (with saline and AN injection; $n=11-12$ pups). The proportions of pups responding during the behavioral assay were compared using either the $\chi^{2}$-test of Pearson (with Yates correction when necessary) when the groups were independent (i.e., distinct groups tested for their response to a same stimulus on different days, or to different stimuli on a given day), or the Cochran's Q-test when the groups were dependent (i.e., pups from a same group tested for their response to the three stimuli). When the Cochran's Q-test was significant, proportions of responding pups were compared $2 \times 2$ by the $\chi^{2}$-test of McNemar. Degrees of freedom are indicated when $>1$. Data were considered as significant when the two-tailed test ended with $p<0.05$.

\section{RESULTS}

\section{EXPERIMENT 1. RETENTION OF A, B AND AB AFTER THEIR RESPECTIVE LEARNING ON DAY 1 OR DAY 3}

To compare the retention of the odors of odorant A, odorant $B$ and of the $A B$ configuration, four groups of pups were conditioned to $A$ on day 1 , four other groups to B and four other groups to $\mathrm{AB}$ ( $n=20$ pups/group, one pup died in one of the groups; all groups were independent). Each group was tested for its behavioral responsiveness to the conditioned stimulus at one single time point only: 24, 48, 72 or 96 h after the conditioning. The same experiment was conducted with 16 other independent groups of pups conditioned on day 3 instead of day $1(n=$ 20/group, one pup died in two groups and two pups in another group).

After conditioning on day 1 (Figure 1, left column), the responsiveness of pups to the conditioned stimulus decreased over time whatever the nature of the stimulus (i.e., in pups conditioned to $\mathrm{A}$, or $\mathrm{B}$ or $\mathrm{AB} ; \chi^{2}>19.37, d f=3, p<0.001$ in the three situations). In pups conditioned to $\mathrm{A}$, the responsiveness to the odorant was maximal and similar 24 and $48 \mathrm{~h}$ after the conditioning ( $\left.>85 \% ; \chi^{2}<1, p>0.05\right)$, lower at $72 \mathrm{~h}\left(55 \% ; \chi^{2}>\right.$ 4.3, $p<0.05$ compared to 24 and $48 \mathrm{~h})$ and $96 \mathrm{~h}\left(35 \% ; \chi^{2}>8.4\right.$, $p<0.01$ compared to 24 and $48 \mathrm{~h}$ ), and not different between 72 and $96 \mathrm{~h}\left(\chi^{2}=1.6, p>0.05\right)$. Regarding the pups conditioned to $B$, the pattern of responsiveness was nearly the same. The responsiveness was maximal and equivalent at 24 and $48 \mathrm{~h}(>85 \%$; $\left.\chi^{2}=1.4, p>0.05\right)$, lower at $72 \mathrm{~h}(60 \%$; comparison with $24 \mathrm{~h}$ : $\chi^{2}=7.6, p<0.01$, with $\left.48 \mathrm{~h}: \chi^{2}=3.1, p=0.07\right)$ and $96 \mathrm{~h}(42.1 \%$; comparison with 24 and $\left.48 \mathrm{~h}: \chi^{2}>6.03, p<0.01\right)$, and similar between 72 and $96 \mathrm{~h}\left(\chi^{2}=1.2, p>0.05\right)$. After conditioning to the $\mathrm{AB}$ mixture, the pups highly and similarly responded to $\mathrm{AB}$ 24 and $48 \mathrm{~h}$ later (95\%) and less at $72 \mathrm{~h}$ (65\%; comparison with 24 and $\left.48 \mathrm{~h}: \chi^{2}=3.9, p<0.05\right)$. At $96 \mathrm{~h}$, only $5 \%$ of the pups responded, a level which was lower compared to 24,48 and $72 \mathrm{~h}$ $\left(\chi^{2}>18.6, p<0.001\right)$. Interestingly, whereas the responsiveness of the three categories of pups (conditioned to A, B and AB) did not differ at 24, 48 and $72 \mathrm{~h}$ (between categories comparisons: $\left.\chi^{2}<1.29, d f=2, p>0.05\right)$, at $96 \mathrm{~h}$ the pups conditioned to $\mathrm{AB}$ responded less to this stimulus than the pups conditioned to $\mathrm{A}$ or $\mathrm{B}\left(\chi^{2}=7.74, d f=2, p<0.05\right.$; comparisons $\mathrm{AB}$ vs. $\mathrm{A}$ or $\mathrm{B}: \chi^{2}>$ 3.91, $p<0.05$; comparison A vs. B: $\left.\chi^{2}<0.5, p>0.05\right)$.

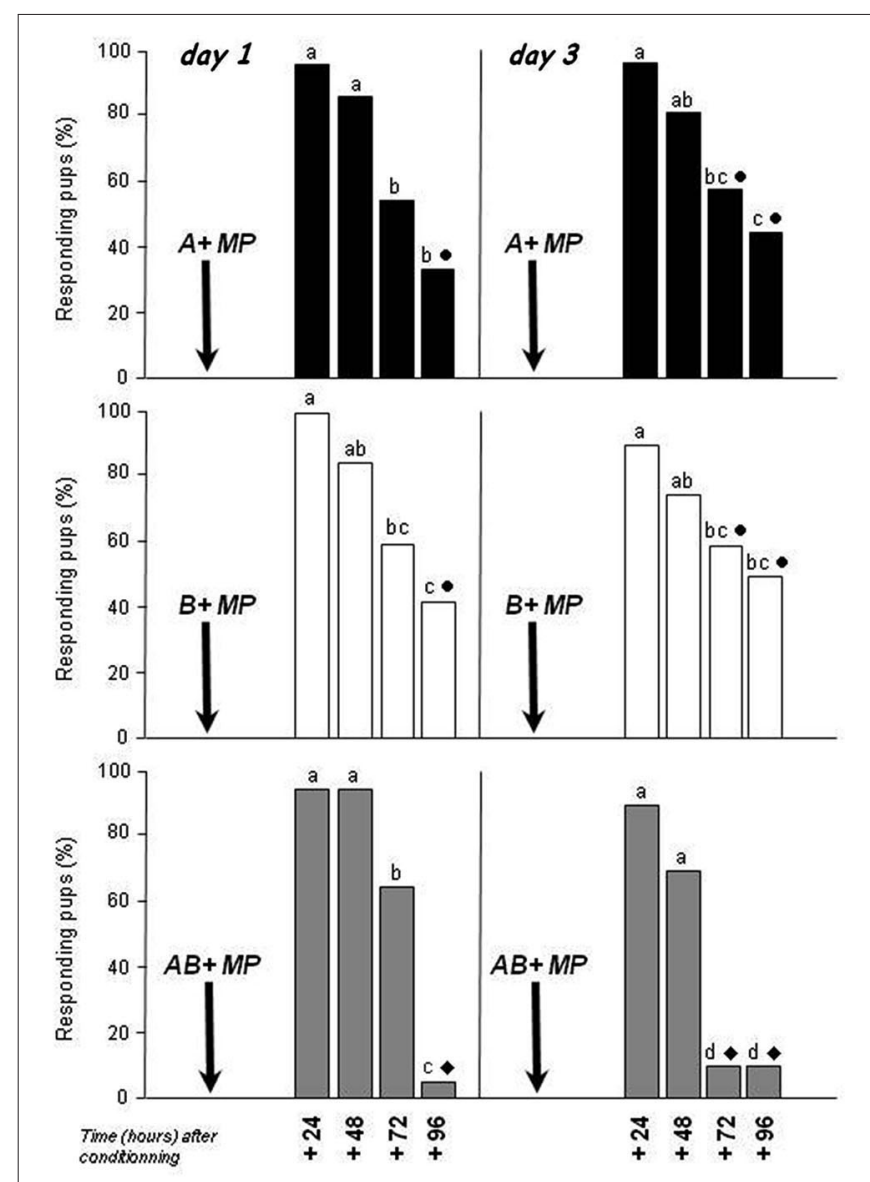

FIGURE 1 | Proportions of rabbit pups responding in an oral activation test to odorant A (ethyl isobutyrate; black bars), odorant B (ethyl maltol; white bars) or the AB mixture (gray bars) 24, 48, 72 and $96 \mathrm{~h}$ after conditioning to one of the stimuli. Conditioning occurred on day 1 or day 3 by pairing with the mammary pheromone (MP). Independent groups of pups ( $n=18$ to 20/group) were tested on each day. Distinct letters indicate significant differences in responsiveness over time between pups conditioned to the same stimulus, and distinct symbols indicate differences on a given period between pups conditioned to different stimuli.

After conditioning on day 3 (Figure 1, right column), the retention of the acquired stimulus changed over time independently of its nature $\left(\chi^{2}>8.28, d f=3, p<0.05\right.$ in the three situations). In pups conditioned to $\mathrm{A}$ or $\mathrm{B}$, the responsiveness was maximal and close at 24 and $48 \mathrm{~h}\left(>75 \% ; \chi^{2}<0.9, p>0.05\right.$ for $\mathrm{A}$ or B comparisons), lower at $72 \mathrm{~h}$ (around $60 \%$ ) compared to $24 \mathrm{~h}$ $\left(\chi^{2}>4.8, p<0.05\right.$ for $\mathrm{A}$ or $\left.\mathrm{B}\right)$, and lower at $96 \mathrm{~h}$ compared to 24 and $48 \mathrm{~h}$ for A $\left(45 \% ; \chi^{2}>5.2, p<0.05\right)$ or compared to $24 \mathrm{~h}$ for $\mathrm{B}\left(50 \% ; \chi^{2}=7.4, p<0.001\right)$. The responsiveness was similar between 96 and $72 \mathrm{~h}$ both in pups conditioned to A and in pups conditioned to $\mathrm{B}\left(\chi^{2}<0.6, p>0.05\right)$. In pups conditioned to $\mathrm{AB}$, the responsiveness to $\mathrm{AB}$ was strong and equivalent at 24 and $48 \mathrm{~h}\left(>70 \% ; \chi^{2}=1.4, p<0.05\right)$, but it became extremely weak as soon as $72 \mathrm{~h}(<10.5 \%$; comparisons between 72 or 96 vs. 24 or $\left.48 \mathrm{~h}: \chi^{2}>11.8, p<0.001\right)$. While the responsiveness to the conditioned stimulus was equivalent between pups conditioned to $\mathrm{A}, \mathrm{B}$ or $\mathrm{AB}$ at 24 and $48 \mathrm{~h}\left(\chi^{2}<0.5, d f=2, p>0.05\right)$, it was 
lower in pups conditioned to $\mathrm{AB}$ than to $\mathrm{A}$ or to $\mathrm{B}$ at 72 and $96 \mathrm{~h}$ $\left(\chi^{2}>8.91, d f=2, p>0.05\right.$; $\mathrm{A}$ or B vs. $\mathrm{AB}: \chi^{2}>4.88, p<0.05$; A vs. B: $\left.\chi^{2}<0.5, p>0.05\right)$.

Thus, whatever the information that was learned $(\mathrm{A}, \mathrm{B}$, or $\mathrm{AB})$ on either day 1 or 3 , its retention by the pups decreased over the 4 post-conditioning days. However, the retention of the $A B$ mixture or of its odorants was not the same: all the pups stopped responding to the mixture 72 and/or $96 \mathrm{~h}$ after conditioning while a significant proportion of them $(>35 \%)$ were still responding to the odorant they have previously learned. Besides the time of memory testing, the animal's age at conditioning also influenced the retention of $\mathrm{AB}$ memory: pups conditioned to $\mathrm{AB}$ at day 3 stopped responding earlier than those conditioned at day $1(72 \mathrm{~h}$ vs. $96 \mathrm{~h}$ ). This effect of age was not observed for A and B memories when comparing conditioning at day 1 and 3 .

\section{EXPERIMENT 2. RETENTION OF A, B AND AB AFTER LEARNING OF AB ON DAY 1 OR 3}

Results of Experiment 1 showed clear differences in the retention of the odors of $\mathrm{A}, \mathrm{B}$ and $\mathrm{AB}$ when each odorant or the mixture were learned separately by different pups, suggesting that the memory retention of the binary mixture is weaker compared to the retention of its components. Here, we assessed whether similar results could be obtained at the individual level (withinsubject design), namely after conditioning to $\mathrm{AB}$ (during which acquisition of the $\mathrm{A}$ and $\mathrm{B}$ elements and of the $\mathrm{AB}$ configuration happens; Coureaud et al., 2008, 2009a, 2011a; Sinding et al., 2011) and during successive testing to the three stimuli. To that goal, the pups conditioned to the $\mathrm{AB}$ mixture on day 1 or 3 in Experiment 1 ( 4 independent groups/day) were tested for their response to $\mathrm{A}$ and to $\mathrm{B}$, in addition to $\mathrm{AB}$, at one single time point only, i.e., either at 24, 48, 72 or $96 \mathrm{~h}$. According to the results of Experiment 1 , it was expected that the retention of the configuration would be shorter than the retention of each element that compose the mixture.

After conditioning to $\mathrm{AB}$ on day 1 (Figure 2, upper part), the pups strongly and similarly responded to $\mathrm{AB}, \mathrm{A}$ and $\mathrm{B}$ at 24 and $48 \mathrm{~h}(>95 \% ; \mathrm{Q}<1.1, d f=2, p>0.05)$. At $72 \mathrm{~h}$, the responsiveness decreased for $\mathrm{AB}$ (Exp. 1) but also for A and for B (responsiveness to $\mathrm{A}$ or $\mathrm{B}$ at 72 vs. 24 or $\left.48 \mathrm{~h}: \chi^{2}>3.9, p<0.05\right)$; it remained however similar between $\mathrm{AB}, \mathrm{A}$ and $\mathrm{B}(65-75 \% ; \mathrm{Q}=1.2, d f=$ $2, p>0.05)$. At $96 \mathrm{~h}$, the responsiveness to $\mathrm{A}$ and to $\mathrm{B}$ was still around 60 and $75 \%$ (thus lower than at 24 and 48 h for A: $\chi^{2}=$ 7.6, $p<0.01$, equivalent for $\mathrm{B}: \chi^{2}=3.1, p=0.07$, and similar for $\mathrm{A}$ and for B compared to $\left.72 \mathrm{~h}: \chi^{2}<1.02, p>0.05\right)$. Strikingly, in the same animals, while responsiveness to A and B was relatively maintained, the responsiveness to $\mathrm{AB}$ was dramatically reduced $\left(5 \% ; Q=23.3, d f=2, p<0.001 ; \mathrm{AB}\right.$ vs. $\mathrm{A}$ or $\mathrm{B}: \mathrm{McNemar} \chi^{2}>$ 9.09, $p<0.01$; A vs. B: McNemar $\left.\chi^{2}=1.3, p>0.05\right)$.

Similar results were observed after conditioning on day 3 (Figure 2, lower part), though with a slightly different time course. After conditioning to $\mathrm{AB}$ on day 3, the responsiveness of pups was high and similar to $A B, A$ and $B 24$ h later ( $>90 \% ; Q=3$, $d f=2, p>0.05)$ and 48 h later $(70-85 \% ; Q=3, d f=2, p>0.05)$. At 72 and $96 \mathrm{~h}$, the responsiveness to $\mathrm{A}$ and $\mathrm{B}$ remained around 50 and $60 \%$ (lower than at $24 \mathrm{~h}, \chi^{2}>5.6, p<0.01$, but not different than at $\left.48 \mathrm{~h}, \chi^{2}<2.1, p>0.05\right)$, but the responsiveness to $\mathrm{AB}$ was weaker ( $<10.5 \%$; for the two periods: $Q>14.88, d f=2, p<$ 0.001 ; $\mathrm{AB}$ vs. $\mathrm{A}$ or $\mathrm{B}$ : McNemar $\chi^{2}>5.14, p<0.05$; A vs. B: McNemar $\left.\chi^{2}<1.3, p>0.05\right)$.

Thus, in line with the data from Experiment 1 obtained with independent groups of pups, the responsiveness of newborn rabbits to the mixture and to its components decreased over time after conditioning to the mixture and individual testing to the three $\mathrm{A}, \mathrm{B}$ and $\mathrm{AB}$ stimuli: it disappeared earlier for the mixture than for the odorants, and earlier after conditioning on day 3 than on 1 .

Moreover, on postnatal day 5, the proportion of pups still responding to $\mathrm{AB}$ was higher in pups conditioned on day 3 than in pups conditioned on day 1 ( 70 vs. $5 \% ; \chi^{2}=15.3, p<0.001$ ) while the responsiveness to A or to B was similar $\left(60-85 \% ; \chi^{2}<0.5, p>\right.$ $0.05)$. This suggests that the difference observed for $A B$ was the consequence of memory processes and not of pure developmental effects.

\section{EXPERIMENT 3. COMPETITION BETWEEN THE MEMORIES OF THE ELEMENTS AND OF THE CONFIGURATION}

According to the results of Experiments 1 and 2, newborn rabbits have a distinct memory and retention of the $\mathrm{AB}$ mixture and of its components. After acquisition of the $\mathrm{AB}$ mixture, this difference in terms of retention could be due to a competition between the memory of each odorant and the memory of the $\mathrm{AB}$ configuration (since the pups perceived both the odorants and the configuration in the weak configurally processed $\mathrm{AB}$ mixture). To evaluate this hypothesis, two procedures were followed.

The first procedure (Experiment 3a) attempted to prevent the creation of a memory for the configuration. In a previous paper (Coureaud et al., 2008), we showed that after successive conditioning to odorant $\mathrm{A}$ then odorant $\mathrm{B}$ on day 1, the pups responded $24 \mathrm{~h}$ later to the $\mathrm{AB}$ mixture (they did not display such a response after conditioning to a single odorant). Here, this paradigm was repeated but with a test of responsiveness $96 \mathrm{~h}$ later. This group ( $n=20$ pups, two of them died, results concerned 18 pups) was compared to the group conditioned to the whole mixture on day 1 and tested on day $5(+96 \mathrm{~h}$ ) in Experiment 2 (i.e., a group that learned the $\mathrm{AB}$ configuration). Whereas the conditioning to the $\mathrm{AB}$ mixture was followed by an absence of responsiveness to $\mathrm{AB}$ but not to A and B at 96 h (Figure 3A, same results as in Figure 2), the successive learning of $\mathrm{A}$ and $\mathrm{B}$ induced a high and similar level of responsiveness to both the mixture and the individual odorants (66.6-72.2\%; $Q=1, d f=2, p>0.05$ ) (Figure 3B). The responsiveness to $\mathrm{AB}$ was therefore higher in the situation of successive learning of the elements than after learning of the mixture $\left(72.2\right.$ vs. $\left.5 \% ; \chi^{2}=15.6, p<0.001\right)$. The responsiveness to the odorants was similar in the two experimental conditions (60$\left.75 \% ; \chi^{2}<0.5, p>0.05\right)$. Therefore, an absence of perception of the $\mathrm{AB}$ configuration during conditioning, due to separate and successive conditioning to odorants $\mathrm{A}$ and $\mathrm{B}$, was followed by the maintenance of responsiveness to the $\mathrm{AB}$ mixture 4 days later.

The second procedure (Experiment $3 \mathrm{~b}$ ) attempted to promote the creation of memories to both the configuration and the elements after $\mathrm{AB}$ conditioning, and to make the pups rapidly amnesic of the individual odorants' odor. We hypothesized that 

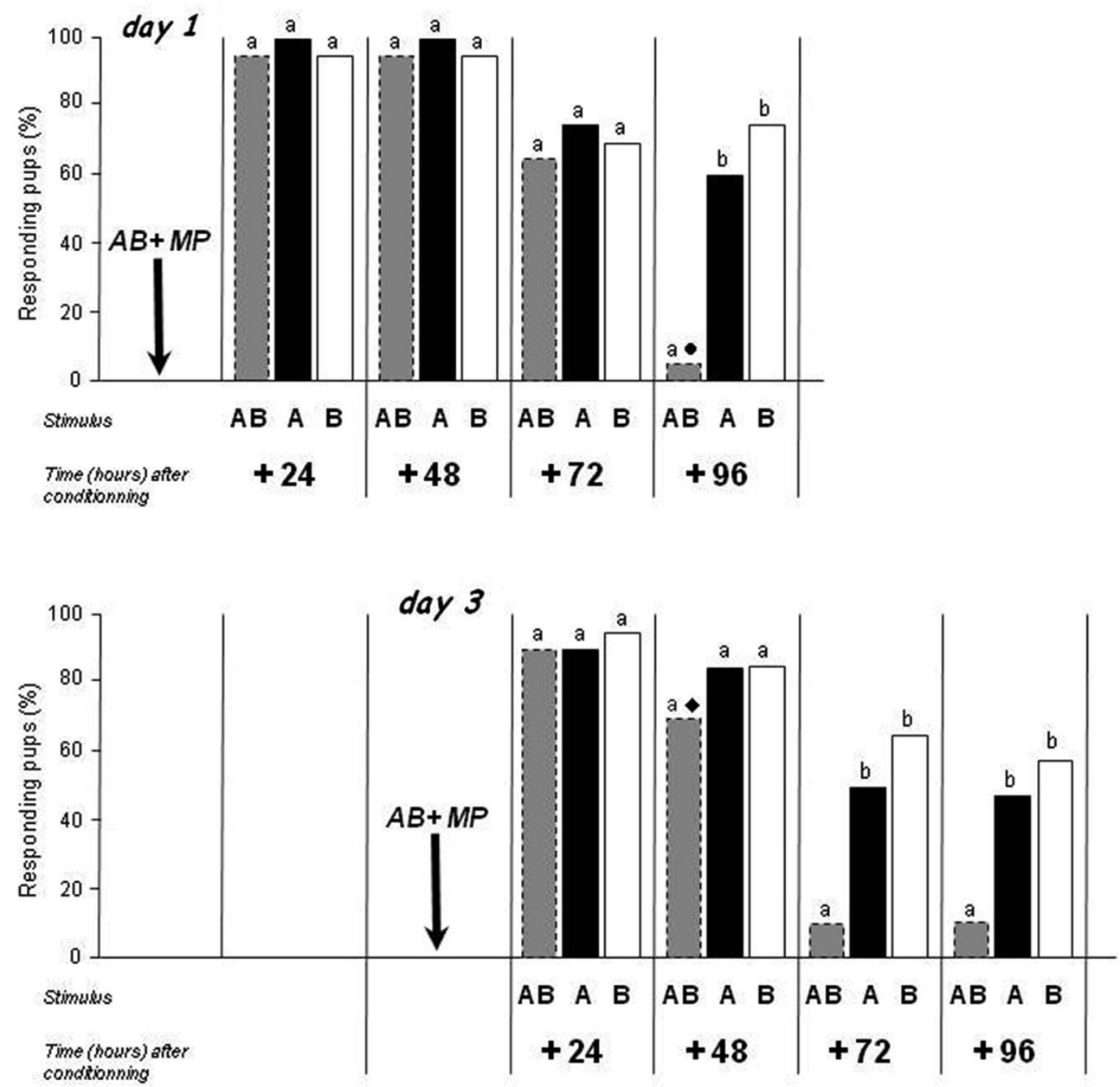

FIGURE 2 | Proportions of rabbit pups responding in an oral activation test to odorant $A$ (ethyl isobutyrate), odorant $B$ (ethyl maltol) and the $A B$ mixture 24, 48, 72 and $96 \mathrm{~h}$ after conditioning to that mixture. Conditioning occurred on day 1 or 3 by pairing with the MP. Independent groups of pups ( $n=19$ or 20/group) were tested on each day. Distinct letters indicate significant differences in responsiveness of the same pups to the three stimuli presented at a given time, and distinct symbols indicate differences in responsiveness to a same stimulus of different pups conditioned on days 1 or 3 and tested during the same postnatal day (dotted bars correspond to results already presented in Figure 1). in this situation, the responsiveness to $\mathrm{AB}$ could be maintained 4 days after the conditioning because of the absence of competition between the configural and elemental memories. Thus, two independent groups of newborns ( $n=12$ /group, 4 pups/litter, 2 pups/litter/group) were conditioned on day 1 to the $A B$ mixture, and reactivated the day after (day 2 ) by separated exposure to each individual odorant ( $A$ then $B$ for half of the pups in each group, B then A for the other half). Immediately after memory reactivation, the first group was injected with saline, while the other group received an AN injection inducing amnesia. The pups were all tested for their responses to $\mathrm{AB}, \mathrm{A}$ and $\mathrm{B}$ on day 5, $96 \mathrm{~h}$ after the conditioning (72 $\mathrm{h}$ after the reactivation). Blocking memory for the individual odorants induced major differences in mixture memory between the groups. The pattern of response in the saline-treated group (Figure 3C) was the same as in pups from previous experiments which were not manipulated on day 2 (Figure 3A): they did not respond to $\mathrm{AB}$ but still displayed a high and similar level of responsiveness to A and to $\mathrm{B}$ (8.3 vs. 75.0 vs. $66.6 \%$, respectively; $Q=12.6, d f=2, p<0.01$; $\mathrm{AB}$ vs. A or B: McNemar $\chi^{2}>5.1, p<0.05$; A vs. B: McNemar $\chi^{2}<$ $0.5, p>0.05$ ). In contrast, newborns treated with AN (1 pup died, $n=11$ for this group in the results) showed a completely reversed pattern of responsiveness to the mixture compared to the elements $(Q=10.3, d f=2, p<0.01)$ (Figure 3D): they responded strongly to the mixture but very weakly to the individual odorants (63.6 vs. 9.1 vs. $9.1 \%$; $\mathrm{AB}$ vs. $\mathrm{A}$ or $\mathrm{B}$ : McNemar $\chi^{2}=4.16, p<$ 0.05). Comparison of the responsiveness between the two groups clearly showed that $\mathrm{AN}$-treated pups responded more to $\mathrm{AB}$ and less to A and to B than saline-treated neonates $\left(\chi^{2}>5.49, p<\right.$ $0.05)$.

Thus, when rabbit pups forgot the odors of the individual elements initially acquired during the conditioning to the $\mathrm{AB}$ mixture, their responsiveness to the mixture was extended over time. This result strongly supports our hypothesis that the learning 
A

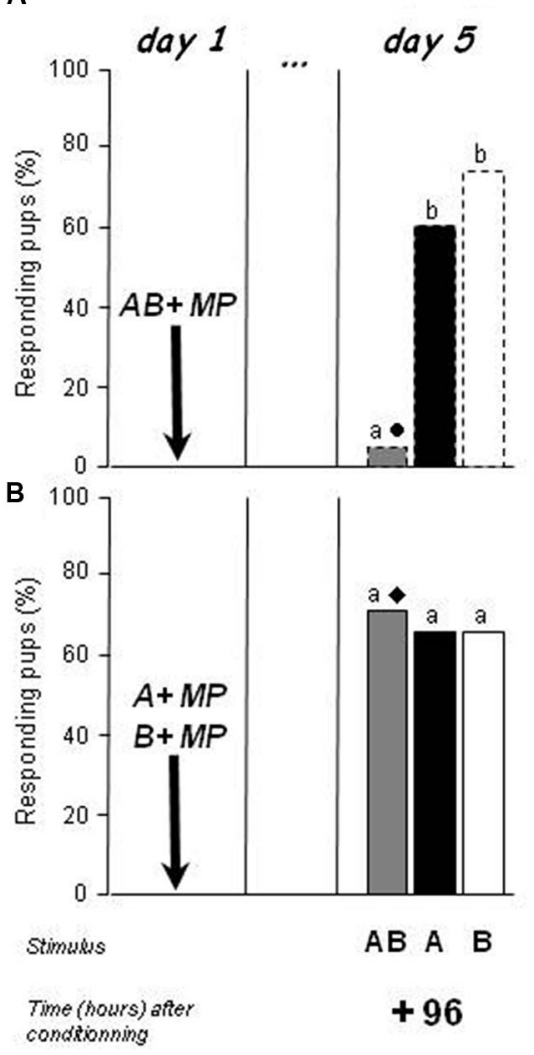

FIGURE 3 | Proportions of rabbit pups responding in an oral activation test to odorant $A$ (ethyl isobutyrate), odorant $B$ (ethyl maltol) and the $A B$ mixture $96 \mathrm{~h}$ after conditioning to $A B$ on day 1 (Figures $3 A, C, D, n=20,12$ and 11 pups, respectively), or after successive conditioning to $A$ then to $B$ on day 1 (Figure $3 B, n=18$ pups). Conditioning was performed by pairing with the MP. In

Figures $\mathbf{3 C}, \mathbf{D}$, the pups were separately exposed to odorants $A$ and $B$
C

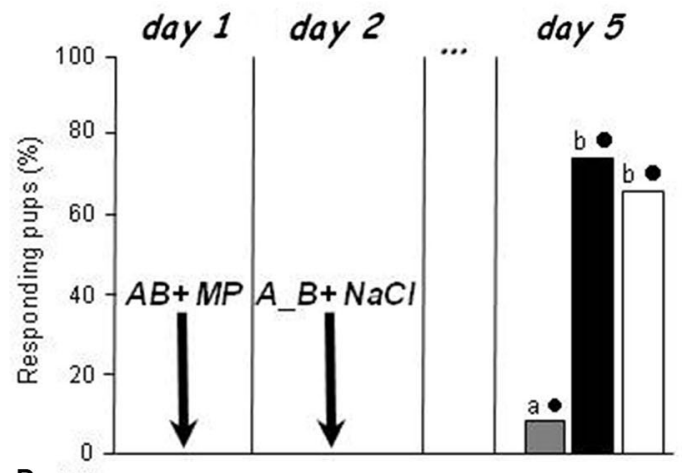

D

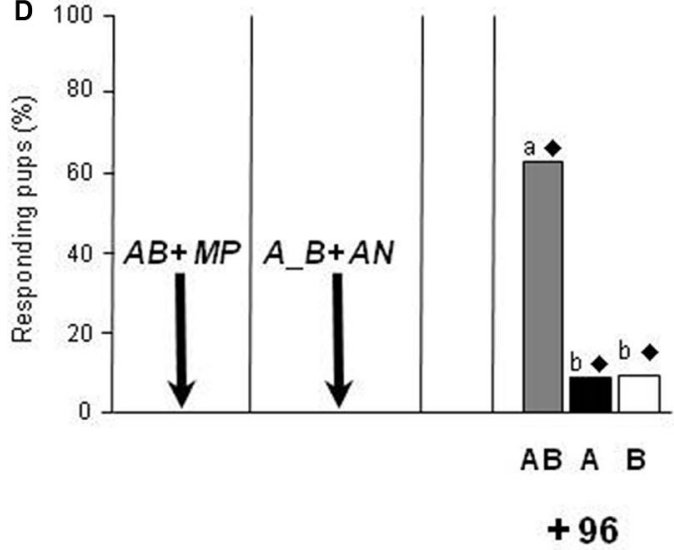

the day after the conditioning and immediately injected either with saline $(\mathrm{NaCl})$ or anisomycin (AN). Distinct letters indicate significant differences in responsiveness to the three stimuli in the same pups, and distinct symbols indicate differences in responsiveness to the same stimulus in pups differently conditioned (3A vs. $\mathbf{3 B}$ ) or differently treated the day after conditioning (3C vs. 3D) (dotted bars correspond to results already presented in Figure 2). of the mixture induced a competition between the memory of the $\mathrm{AB}$ configuration and the memory of the elements $\mathrm{A}$ and $\mathrm{B}$.

\section{DISCUSSION}

The present results, obtained in rabbit pups using the $\mathrm{AB}$ weak configural mixture, demonstrate that the memory of odor elements is more robust and lasts longer than the configural memory of the mixture, and in fact can interfere with the maintenance of the configural memory. In the absence of elemental odor memory, the duration of the configural memory of the $\mathrm{AB}$ mixture is significantly enhanced. Although further work is required to determine whether these results generalize to other mixtures (weak configurally, configurally or, in contrast, elementally perceived mixtures), the present findings have important implications for understanding the mechanisms of odor mixture (and odor object) perception and the organization of odor mixture memory.

Advantage of elemental over configural memory of the $\mathrm{AB}$ mixture was first observed in the duration of memory following conditioning to the elements alone or to the mixture (Experiment 1). For example, conditioning to either element (A or B) alone induced a memory of that element that extended for at least 96 h. In contrast, conditioning to the binary mixture induced memory that extended no more than $72 \mathrm{~h}$. Interestingly, the duration of memory for the mixture was age-dependent, while the duration of elemental memory was not. Animals conditioned to the mixture on day 1 reactivated memory for the mixture for $72 \mathrm{~h}$, while animals conditioned on day 3 displayed mixture memory for no more than $48 \mathrm{~h}$. Additional work is required to determine the mechanisms of this age-dependent variation in the duration of configural memory. Regarding general memory mechanisms, one may hypothesize that the information is more easily processed when the animal is exposed to a single odorant compared to a mixture of odorants. To be encoded correctly, a weak configural mixture could require a higher arousal level than individual odorants perceived separately, since the animals might have to share attentional level between the different stimuli of the mixture to engage associative learning for all stimuli (Sharot and Phelps, 2004). As a result, after only 
one conditioning session, the memory trace of a complex odor stimulus might be rather fragile and its decay might be faster over time in comparison with more simple stimuli. Here, the present conditioning was appetitive. One may therefore wonder whether similar results would be obtained with aversive conditioning, using odor-malaise association for instance (see Gruest et al., 2004), since a stronger arousal is then supposed to occur during acquisition. It would be of interest to evaluate in future experiments whether this other kind of conditioning induces longer lasting configural memory of the $\mathrm{AB}$ mixture.

Advantage of elemental over configural memory of odor mixture was also found after associative conditioning with the $\mathrm{AB}$ mixture, and within-subject testing to both the mixture and its elements (Experiments 2 and 3). After conditioning to this mixture known to be perceived configurally in humans (Le Berre et al., 2008; Barkat et al., 2012), rabbit pups expressed a weak configural memory of the mixture, meaning that they expressed both a memory for the mixture's configuration and for the individual elements. In particular, they did not respond to $\mathrm{AB}$ at $96 \mathrm{~h}$ or $72 \mathrm{~h}$ (after conditioning on day 1 or 3, respectively) but still responded to $A$ and to $B$ at these retention times (Experiment 2). In terms of odor mixture processing, these results may seem surprising. Indeed, if the mixture is perceived in a weak configural way during the retention test, rabbit pups should perceive in the mixture both the elements they have previously learned and the $\mathrm{AB}$ configuration. Moreover, when pups have learned independently enough elements forming a mixture, they can respond (generalize) to the mixture even if the mixture is perceived in part configurally (Experiment 3a showing responsiveness to $\mathrm{AB}$ after successive learning of $\mathrm{A}$ and $\mathrm{B}$; see also Coureaud et al., 2008). Therefore, after conditioning to $A B$ on day 1 and because the pups responded to $\mathrm{A}$ and to $\mathrm{B}$ at $96 \mathrm{~h}$, a response to the mixture could be expected. To explain the lack of response to $A B$ at $96 \mathrm{~h}$, we hypothesize that the $A B$ mixture is, initially, weakly configurally perceived during the conditioning with the MP, but that a particular associative strength is then given to the configuration compared to the elements. As a consequence, the pups would perceive the mixture more as the configuration when they are exposed again to the mixture several days after conditioning. This hypothesis is supported by theoretical considerations suggesting that during conditioning to complex stimulus, a specific value is assigned to the configural representation ("unique cue") independently of that given to each element (Rescorla, 1973; Rescorla et al., 1985). Alternatively, one may assume that during the conditioning, the presence of the MP leads rabbit neonates to perceive the $\mathrm{AB}$ mixture less configurally (i.e., weak configurally) compared to its processing in the absence of unconditioned stimulus (robust configural perception).

Importantly, the present results suggest that the long-term memory of the elemental and configural representations of the $\mathrm{AB}$ mixture compete. That is, with intact elemental memory, configural memory of the mixture degrades significantly faster than memory of the elements (Experiment 2). In contrast, if elemental memory is disrupted by selective reconsolidation blockade, configural memory of the mixture is maintained significantly longer (Experiment 3b). This indicates that removing a potential source of interference facilitates memory performance for the $\mathrm{AB}$ configural information. The retrieved memory of the $\mathrm{AB}$ mixture can thus be regarded as the sum of conflicting processes involving, in our case, the elemental memory and the configural memory. The outcome seems dependent on the dominance of one of the memories at the time of retrieval, here the elemental memory, a result that contributes to unravel aspects of memory organization (e.g., Eisenberg et al., 2003; Suzuki et al., 2004; Bradfield and Balleine, 2013). The competition would rely on the retention time (Experiments 1 and 2) and the simultaneous (but not successive; Experiment 3a) exposure to odorants forming a weak configurally perceived mixture. This interference/competition may happen theoretically and first during consolidation of configural and elemental memories of the mixture. However, this assumption has certainly to be ruled out, since we have previously shown in newborn rabbits that consolidation of odor stimuli learned by association with the MP happened in the first $4 \mathrm{~h}$ after conditioning (Coureaud et al., 2009b); the consolidation phase is thus terminated well before the erasure of A and B memories performed here (i.e., $24 \mathrm{~h}$ after conditioning; Experiment $3 \mathrm{~b}$ ). Therefore, in the present paradigm, interference/competition between configural and elemental memories of the mixture certainly occurs during maintenance and/or recall of the memories rather than during consolidation phase, with elemental memory the stronger of the two. Even if the most probable explanation for the absence of response to $A B$ at $96 \mathrm{~h}$ is the absence of recognition of the $A B$ configuration, one can not exclude the possibility that rabbit pups still find familiarity in $\mathrm{AB}$ but without any motivational significance.

The present results do not allow direct determination of the mechanisms of elemental and configural memory interaction, although hypotheses based on the known neurobiology of odor mixture processing can be developed. In rodents, odor mixtures are processed differently by the olfactory bulb and primary olfactory (piriform) cortex (Wilson and Sullivan, 2011). For example, the activity of olfactory bulb mitral/tufted cell neural ensembles is strongly consistent with pattern separation processingresponding uniquely to even minor changes in mixture elements (Barnes et al., 2008; Chapuis and Wilson, 2011; Sahay et al., 2011). Thus, it has been hypothesized that olfactory bulb neural ensembles respond to odor mixture features or components, rather than to the mixture configuration. In strong contrast, piriform cortical neural ensembles respond in a manner consistent with configural processing. In fact, even at the single-unit level of the piriform cortex, individual cells can distinguish between mixtures and their components in cross-adaptation procedures (Wilson, 2003). Mitral/tufted cells, on the other hand, show strong cross-adaptation between mixtures and their components, again consistent with an elemental or feature-dependent process within the olfactory bulb (Wilson, 2003). After having reported in newborn rabbits mapping of activations induced by the MP or by a MP-learned odorant in the olfactory bulb and central regions, including the piriform cortex (Charra et al., 2012, 2013) we are currently assessing the brain activity mapping of the $\mathrm{AB}$ mixture (Schneider et al., in preparation). 
Odor memory is dependent on plasticity within both the olfactory bulb and piriform cortex (Wilson et al., 2004), even in neonates (Moriceau and Sullivan, 2005; Charra et al., 2013; Fontaine et al., 2013). In the context of the present results, and waiting for further results obtained with the $A B$ mixture as with other odor mixtures, we hypothesize that the more stable elemental memory of an odor mixture may mainly depend on olfactory bulb plasticity, while configural memory of the same mixture may mainly depend on piriform cortical processes (in accordance with the presumed role of piriform cortex as an associative cortex; Johnson et al., 2000). These cortical processes may be less robust during early development than memorydependent events in the olfactory bulb, resulting in the distinction between these two memory forms in the present study. The less robust configural memory might depend on differences in the developmental program of both the olfactory bulb and piriform cortex: functional odor maps in the glomerular layer seems rather well defined after birth (Guthrie and Gall, 1995) whereas the maturation of inhibitory processes and the intracortical associational fibers throughout the 3-layered piriform cortex (Schwob and Price, 1984) might follow a slightly different time curve (Garske et al., 2013). One may also suggest that this distinction does not rely on robustness of cortical processing only, but on changes during animal development in the dialogue between sensory/mnesic regions of the brain (olfactory bulb/piriform cortex/amygdala/hippocampus), in accordance with the behavioral and adaptive needs of the animal (Schacher and $\mathrm{Hu}, 2014$ ). Future work could combine the powerful reconsolidation-mediated dissection of memory utilized here, with neurophysiological techniques to explore neurobiological underpinnings of these basic memory and perceptual processes.

Finally, the present findings are further evidence that while odor mixtures are perceived sometimes configurally, and conscious analysis of odor mixtures is notoriously difficult (e.g., Jinks and Laing, 1999), information about the underlying individual components can remain intact in both neonatal rabbits (shown here) and adult humans (Grabenhorst et al., 2007). In the case of newborn rabbits, this may be especially important given the life and death importance of odor recognition to interact with the mother, attach to the nipples, survive and grow up. Having access to both the elements and the configuration may help ensure successful recognition, improved discrimination between odorous substrates or conspecifics in the surroundings, adaptation to the actual environment or anticipation of social and feeding changes that will come later in development.

\section{ACKNOWLEDGMENTS}

We sincerely thank Valérie Saint-Giorgio, Nicolas Malaty, Florent Costilhes, Jérôme Antoine and all the Centre de Zootechnie from the University of Burgundy for their cooperation. The work was supported by French ANR-2010-JCJC-1410-1 MEMOLAP to Gérard Coureaud, Thierry Thomas-Danguin, Frédérique Datiche and Guillaume Ferreira.

\section{REFERENCES}

Barkat, S., Le Berre, E., Coureaud, G., Sicard, G., and Thomas-Danguin, T. (2012). Perceptual blending in odor mixtures depends on the nature of odorants and human olfactory expertise. Chem. Senses 37, 159-166. doi: 10. 1093/chemse/bjr086

Barnes, D. C., Hofacer, R. D., Zaman, A. R., Rennaker, R. L., and Wilson, D. A. (2008). Olfactory perceptual stability and discrimination. Nat. Neurosci. 11, 1378-1380. doi: 10.1038/nn.2217

Barr, G. A., Moriceau, S., Shionoya, K., Muzny, K., Gao, P., Wang, S., et al. (2009). Transitions in infant learning are modulated by dopamine in the amygdala. Nat. Neurosci. 12, 1367-1369. doi: 10.1038/nn.2403

Bradfield, L. A., and Balleine, B. W. (2013). Hierarchical and binary associations compete for behavioral control during instrumental biconditional discrimination. J. Exp. Psychol. Anim. Behav. Process. 39, 2-13. doi: 10.1037/a00 30941

Chapuis, J., and Wilson, D. A. (2011). Bidirectional plasticity of cortical pattern recognition and behavioral sensory acuity. Nat. Neurosci. 15, 155-161. doi: 10. 1038/nn.2966

Charra, R., Datiche, F., Castanho, A., Gigot, V., Schaal, B., and Coureaud, G. (2012). Brain processing of the mammary pheromone in newborn rabbits. Behav. Brain Res. 226, 179-188. doi: 10.1016/j.bbr.2011.09.008

Charra, R., Datiche, F., Gigot, V., Schaal, B., and Coureaud, G. (2013). Pheromoneinduced odour learning modifies Fos expression in the newborn rabbit brain. Behav. Brain Res. 237, 129-140. doi: 10.1016/j.bbr.2012.09.017

Coureaud, G., Charra, R., Datiche, F., Sinding, C., Thomas-Danguin, T., Languille, S., et al. (2010). A pheromone to behave, a pheromone to learn: the rabbit mammary pheromone. J. Comp. Physiol. A Neuroethol. Sens. Neural Behav. Physiol. 196, 779-790. doi: 10.1007/s00359-010-0548-y

Coureaud, G., Gibaud, D., Le Berre, E., Schaal, B., and Thomas-Danguin, T. (2011a). Proportion of odorants impacts the configural versus elemental perception of a blending mixture in newborn rabbits. Chem. Senses 36, 693-700. doi: 10.1093/chemse/bjr049

Coureaud, G., Hamdani, Y., Schaal, B., and Thomas-Danguin, T. (2009a). Elemental and configural processing of odour mixtures in the newborn rabbit. J. Exp. Biol. 212, 2525-2531. doi: 10.1242/jeb.032235

Coureaud, G., Hars, B., Languille, S., and Schaal, B. (2009b). Pheromone-induced olfactory memory in newborn rabbits: involvement of consolidation and reconsolidation processes. Learn. Mem. 16, 470-473. doi: 10.1101/lm.1434009

Coureaud, G., Languille, S., Joly, V., Schaal, B., and Hars, B. (2011b). Independence of first- and second-order memories in newborn rabbits. Learn. Mem. 18, 401404. doi: $10.1101 / \mathrm{lm} .2145111$

Coureaud, G., Moncomble, A.-S., Montigny, D., Dewas, M., Perrier, G., and Schaal, B. (2006). A pheromone that rapidly promotes learning in the newborn. Curr. Biol. 16, 1956-1961. doi: 10.1016/j.cub.2006.08.030

Coureaud, G., Thomas-Danguin, T., Le Berre, E., and Schaal, B. (2008). Perception of odor blending mixtures in the newborn rabbit. Physiol. Behav. 95, 194-199. doi: 10.1016/j.physbeh.2008.05.018

Coureaud, G., Thomas-Danguin, T., Wilson, D. A., and Ferreira, G. (in press). Neonatal representation of odour objects: distinct memories of the whole and its parts. Proc. R. Soc. B.

Coureaud, G., Tourat, A., and Ferreira, G. (2013). Sensory preconditioning in newborn rabbits: from common to distinct odor memories. Learn. Mem. 20, 453-458. doi: 10.1101/lm.030965.113

Davis, H. P., and Squire, L. R. (1984). Protein synthesis and memory: a review. Psychol. Bull. 96, 518-559. doi: 10.1037//0033-2909.96.3.518

Deisig, N., Lachnit, H., Giurfa, M., and Hellstern, F. (2001). Configural olfactory learning in honeybees: negative and positive patterning discrimination. Learn. Mem. 8, 70-78. doi: 10.1101/lm.8.2.70

Derby, C., Huston, M., Livermore, B., and Lynn, W. (1996). Generalization among related complex odorant mixtures and their components: analysis of olfactory perception in the spiny lobster. Physiol. Behav. 60, 87-95. doi: 10.1016/00319384(95)02237-6

Desgranges, B., Lévy, F., and Ferreira, G. (2008). Anisomycin infusion in amygdala impairs consolidation of odor aversion memory. Brain Res. 1236, 166-175. doi: 10.1016/j.brainres.2008.07.123

Eisenberg, M., Kobilo, T., Berman, D. E., and Dudai, Y. (2003). Stability of retrieved memory: inverse correlation with trace dominance. Science 301, 1102-1104. doi: $10.1126 /$ science. 1086881

Fontaine, C. J., Harley, C. W., and Yuan, Q. (2013). Lateralized odor preference training in rat pups reveals an enhanced network response in anterior piriform cortex to olfactory input that parallels extended memory. J. Neurosci. 33, 1512615131. doi: 10.1523/JNEUROSCI.2503-13.2013 
Garske, A. K., Lawyer, C. R., Peterson, B. M., and Illig, K. R. (2013). Adolescent changes in dopamine D1 receptor expression in orbitofrontal cortex and piriform cortex accompany an associative learning deficit. PLoS One 8:e56191. doi: 10.1371/journal.pone.0056191

Gottfried, J. A. (2010). Central mechanisms of odour object perception. Nat. Rev. Neurosci. 11, 628-641. doi: 10.1038/nrn2883

Grabenhorst, F., Rolls, E. T., Margot, C., da Silva, M. A., and Velazco, M. I. (2007). How pleasant and unpleasant stimuli combine in different brain regions: odor mixtures. J. Neurosci. 27, 13532-13540. doi: 10.1523/jneurosci.3337-07. 2007

Gruest, N., Richer, P., and Hars, B. (2004). Memory consolidation and reconsolidation in the rat pup require protein synthesis. J. Neurosci. 24, 10488-10492. doi: 10.1523/jneurosci.2984-04.2004

Guthrie, K. M., and Gall, C. M. (1995). Functional mapping of odor-activated neurons in the olfactory bulb. Chem. Senses 20, 271-282. doi: 10.1093/chemse/20. 2.271

Jinks, A., and Laing, D. G. (1999). A limit in the processing of components in odour mixtures. Perception 28, 395-404. doi: 10.1068/p2898

Johnson, D. M., Illig, K. R., Behan, M., and Haberly, L. B. (2000). New features of connectivity in piriform cortex visualized by intracellular injection of pyramidal cells suggest that "primary" olfactory cortex functions like "association" cortex in other sensory systems. J. Neurosci. 20, 6974-6982.

Kay, L. M., Crk, T., and Thorngate, J. (2005). A redefinition of odor mixture quality. Behav. Neurosci. 119, 726-733. doi: 10.1037/0735-7044.119. 3.726

Laing, D. G., and Francis, G. W. (1989). The capacity of humans to identify odors in mixtures. Physiol. Behav. 46, 809-814. doi: 10.1016/0031-9384(89) 90041-3

Laska, M., and Hudson, R. (1993). Discriminating parts from the whole: determinants of odor mixture perception in squirrel monkeys, Saimiri sciureus. J. Comp. Physiol. A 173, 249-256. doi: 10.1007/bf00192984

Le Berre, E., Jarmuzek, E., Béno, N., Etiévant, P., Prescott, J., and Thomas-Danguin, T. (2010). Learning influences the perception of odor mixtures. Chem. Percept. 3, 156-166. doi: 10.1007/s12078-010-9076-y

Le Berre, E., Thomas-Danguin, T., Beno, N., Coureaud, G., Etievant, P., and Prescott, J. (2008). Perceptual processing strategy and exposure influence the perception of odor mixtures. Chem. Senses 33, 193-199. doi: 10.1093/chemse/ bjm080

Linster, C., and Cleland, T. A. (2004). Configurational and elemental odor mixture perception can arise from local inhibition. J. Comput. Neurosci. 16, 39-47. doi: 10.1023/b:jcns.0000004840.87570.2e

Linster, C., and Smith, B. H. (1999). Generalization between binary odor mixtures and their components in the rat. Physiol. Behav. 66, 701-707. doi: 10. 1016/s0031-9384(99)00007-4

Mandairon, N., Sacquet, J., Garcia, S., Ravel, N., Jourdan, F., and Didier, A. (2006). Neurogenic correlates of an olfactory discrimination task in the adult olfactory bulb. Eur. J. Neurosci. 24, 3578-3588. doi: 10.1111/j.1460-9568.2006. 05235.x

Montigny, D., Coureaud, G., and Schaal, B. (2006). Rabbit pup response to the mammary pheromone: from automatism to prandial control. Physiol. Behav. 89, 742-749. doi: 10.1016/j.physbeh.2006.08.022

Moriceau, S., and Sullivan, R. M. (2005). Neurobiology of infant attachment. Dev. Psychobiol. 47, 230-242. doi: 10.1002/dev.20093

Rescorla, R. A. (1973). Evidence for unique stimulus account of configural conditioning. J. Comp. Physiol. Psychol. 85, 331-338. doi: 10.1037/h00 35046

Rescorla, R. A., Gruau, J. W., and Durlach, P. J. (1985). Analysis of the unique cue in configural discriminations. J. Exp. Psychol. Anim. Behav. Process. 11, 356-366. doi: 10.1037//0097-7403.11.3.356

Riffell, J. A., Lei, H., and Hildebrand, J. G. (2009). Neural correlates of behavior in the moth Manduca sexta in response to complex odors. Proc. Natl. Acad. Sci. U S A 106, 19219-19226. doi: 10.1073/pnas.0910592106
Sahay, A., Wilson, D. A., and Hen, R. (2011). Pattern separation: a common function for new neurons in hippocampus and olfactory bulb. Neuron 70, 582588. doi: 10.1016/j.neuron.2011.05.012

Schacher, S., and Hu, J. Y. (2014). The less things change, the more they are different: contributions of long-term synaptic plasticity and homeostasis to memory. Learn. Mem. 21, 128-134. doi: 10.1101/lm.027326.112

Schwob, J. E., and Price, J. L. (1984). The development of lamination of afferent fibers to the olfactory cortex in rats, with additional observations in the adult. $J$. Comp. Neurol. 223, 203-222. doi: 10.1002/cne.902230205

Sharot, T., and Phelps, E. A. (2004). How arousal modulates memory: disentangling the effects of attention and retention. Cogn. Affect. Behav. Neurosci. 4, 294-306. doi: 10.3758/cabn.4.3.294

Sinding, C., Thomas-Danguin, T., Crepeaux, G., Schaal, B., and Coureaud, G. (2011). Experience influences elemental and configural perception of certain binary odour mixtures in newborn rabbits. J. Exp. Biol. 214, 4171-4178. doi: 10. 1242/jeb.063610

Smith, B. H. (1996). The role of attention in learning about odorants. Biol. Bull. 191, 76-83. doi: 10.2307/1543065

Sullivan, R. M., and Holman, P. J. (2010). Transitions in sensitive period attachment learning in infancy: the role of corticosterone. Neurosci. Biobehav. Rev. 34, 835844. doi: 10.1016/j.neubiorev.2009.11.010

Suzuki, A., Josselyn, S. A., Frankland, P. W., Masushige, S., Silva, A. J., and Kida, S. (2004). Memory reconsolidation and extinction have distinct temporal and biochemical signatures. J. Neurosci. 24, 4787-4795. doi: 10.1523/jneurosci.549103.2004

Valentincic, T., Kralj, J., Stenovec, M., Koce, A., and Caprio, J. (2000). The behavioral detection of binary mixtures of amino acids and their individual components by catfish. J. Exp. Biol. 203, 3307-3317. doi: 10.1111/j.1095.8649. 2011.02976.x

Wilson, D. A., and Sullivan, R. M. (2011). Cortical processing of odor objects. Neuron 72, 506-519. doi: 10.1016/j.neuron.2011.10.027

Wilson, D. A. (2003). Rapid, experience-induced enhancement in odorant discrimination by anterior piriform cortex neurons. J. Neurophysiol. 90, 65-72. doi: 10 . 1152/jn.00133.2003

Wilson, D. A., Best, A. R., and Sullivan, R. M. (2004). Plasticity in the olfactory system: lessons for the neurobiology of memory. Neuroscientist 10, 513-524. doi: $10.1177 / 1073858404267048$

Wiltrout, C., Dogras, S., and Linster, C. (2003). Configurational and nonconfigurational interactions between odorants in binary mixtures. Behav. Neurosci. 117, 236-245. doi: 10.1037/0735-7044.117.2.236

Wise, P. M., and Cain, W. S. (2000). Latency and accuracy of discriminations of odor quality between binary mixtures and their components. Chem. Senses 25 , 247-265. doi: 10.1093/chemse/25.3.247

Zarrow, M. X., Denenberg, V. H., and Anderson, C. O. (1965). Rabbit: frequency of suckling in the pup. Science 150, 1835-1836. doi: 10.1126/science.150.3705.1835

Conflict of Interest Statement: The authors declare that the research was conducted in the absence of any commercial or financial relationships that could be construed as a potential conflict of interest.

Received: 10 April 2014; accepted: 26 May 2014; published online: 16 June 2014.

Citation: Coureaud G, Thomas-Danguin T, Datiche F, Wilson DA and Ferreira G (2014) Differential memory persistence of odor mixture and components in newborn rabbits: competition between the whole and its parts. Front. Behav. Neurosci. 8:211. doi: 10.3389/fnbeh.2014.00211

This article was submitted to the journal Frontiers in Behavioral Neuroscience.

Copyright (c) 2014 Coureaud, Thomas-Danguin, Datiche, Wilson and Ferreira. This is an open-access article distributed under the terms of the Creative Commons Attribution License (CC BY). The use, distribution or reproduction in other forums is permitted, provided the original author(s) or licensor are credited and that the original publication in this journal is cited, in accordance with accepted academic practice. No use, distribution or reproduction is permitted which does not comply with these terms. 